\title{
Visions for IAHSI, the International Academy of Health Sciences Informatics*
}

\author{
Reinhold Haux \\ Peter L. Reichertz Institute for Medical Informatics, University of Braunschweig - Institute \\ of Technology and Hannover Medical School, Germany \\ Past President and Honorary Fellow of IMIA, the International Medical Informatics Association \\ Fellow of IAHSI, the International Academy of Health Sciences Informatics
}

\begin{abstract}
Summary
These visions for IAHSI, the newly founded International Academy of Health Sciences Informatics ("the Academy"), include the following principles, in order of descending priority: (1) The Academy should attempt to contribute to the health of the people in our world, (2) the Academy should be engaged in advising governments and organizations on developing health and science through informatics, (3) the Academy should stimulate progress in informatics research, education, and practice, (4) Academy members should share and exchange knowledge, (5) the Academy's structure and organization should follow the tradition of scientific societies, (6) Academy membership is one of the highest honors in informatics internationally, (7) the Academy should meet where the International Medical Informatics Association meets, and (8) the Academy's structure and organization should be lean and unbiased. These visions have been put forward for discussion specifically but not exclusively to the inaugural class of the Academy, organized at the 2018 Medical Informatics Europe conference, with its distinguished members.
\end{abstract}

\section{Keywords}

Biomedical and health informatics; medical informatics; health informatics; academies of science; International Academy of Health Sciences Informatics

Yearb Med Inform 2018:7-9

http://dx.doi.org/10.1055/s-0038-1641214

\section{Objective}

This paper will present the author's visions for IAHSI, the newly founded International Academy of Health Sciences Informatics ("the Academy", [1, 2]). These visions have been put forward for discussion specifically, but not exclusively, to the inaugural class of the Academy, organized at the 2018 Medical Informatics Europe conference, with its distinguished members, many of whom have influenced the author's career significantly.

\section{Background}

Before presenting these visions, it is necessary to discuss two experiences of the author that significantly shaped the visions presented here.

- In 2009, the author was elected a member of the Braunschweig Scientific Society (Braunschweigische Wissenschaftliche Gesellschaft, BWG, [3, 4]). BWG is a scientific society which, according to its bylaws and objectives, is analogous to other academies of sciences. BWG has the right of co-option allowing members to nominate and elect other scholars based on their academic reputation as the only path to membership. Established by the State of Lower Saxony as an independent institution with a civic mission, its objectives are to promote collaboration of natural sciences, engineering sciences, and humanities. This

* Written version of a talk presented at the $1^{\text {st }}$ meeting of the International Academy of Health Sciences Informatics on April 24, 2018, at MIE 2018 in Gothenburg, Sweden. is accomplished through meetings and committees tasked with certain assignments. BWG supports the transfer of scientific knowledge and advises the public in various ways. Annually, the Carl Friedrich Gauß Medal is awarded by BWG to outstanding scientists. The number of full members younger than 70 years old is limited to a maximum of 100 scholars.

- In 2013, the author was nominated by the World Health Organization (WHO) to become a member of WHO's eHealth Technical Advisory Group (eTAG, [5]). One objective of this group of 32 experts from all WHO regions is to review WHO's eHealth activities and to make recommendations on priorities. eTAG's first meeting took place December 12-13, 2013, in WHO's headquarter in Geneva, Switzerland. During the meeting's intensive discussions on how health care can be improved globally through eHealth, the author recognized the need for WHO officials to receive high-level and unbiased information on informatics' contributions and best practices on its use to stimulate improvements in people's health and well-being. The author further realized that a scholarly society such as BWG but devoted to biomedical and health informatics and established on an international level might help with this mission. IMIA, the International Medical Informatics Association [6], seemed to be a well-suited parent organization for establishing such an international academy.

During the eTAG meeting, the author discussed this idea with Hyeoun-Ae Park (then IMIA President-Elect) and Antoine Geissbuhler (then immediate Past-President of IMIA), who are both also members 
of WHO's eTAG. These discussions were followed up by calls to Lincoln Assis Moura (then President of IMIA), Peter Murray (then CEO of IMIA), and Alexa McCray (then President of ACMI, [7]). On January 10, 2014, the author submitted a proposal for establishing such an international academy under the roof of IMIA [8]. In the meantime, the idea of a scientific society in medical informatics has become reality. With the commitment of many colleagues, in particular of Ted Shortiffe and Patrice Degoulet, who served as co-chairs of IMIA's IAHSI Task Force ${ }^{1}$, of IMIA's Presidents Christoph U. Lehmann and Hyeoun-Ae Park, and with the strong support of IMIA's CEO Elaine Huesing, the Academy was established, and in 2017 its first 120 members were elected as the inaugural class.

\section{Visions}

In this early phase for the Academy, it is of utmost importance that its objectives and activities will be well chosen. The author's visions, denoted with $\mathrm{V}_{i}, i \in$ $\{1,2, \ldots, 8\}$, are intended to aid in the discussion of the Academy's objectives, activities, and priorities. As they are one individual's visions, they certainly will be subjective. For brevity, the term informatics is used instead of biomedical and health informatics ${ }^{2}$.

\section{$V_{1}$ : The Academy should attempt to contribute to the health of the people in our world}

The Academy should serve the people in the world and promote health, dignity, and participation. How this can best be achieved will remain an ongoing debate. The objective

\footnotetext{
1 Members, appointed by the IMIA Board, were: Patrice Degoulet (IMIA Past Vice President \& Honorary Fellow), Christoph U. Lehmann (IMIA President), Alexa McCray (IMIA Past Vice President \& Honorary Fellow), Lincoln Assis Moura (IMIA Past President), HyeounAe Park (IMIA Past President), Ted Shortliffe (IMIA Honorary Fellow), Elaine Huesing (ex officio, IMIA CEO), and the author.

2 ... or any other naming of our field. For those being interested, my definition and further comments on our field can be found in [9], section 2 .
}

to contribute to the health of people worldwide through informatics should always be the Academy's first priority. The Academy's activities should permanently be evaluated on how well this objective is achieved.

\section{$V_{2}$ : The Academy should be engaged in} advising governments and organizations on developing health and science through informatics

The Academy should serve governments and (primarily international) organizations by providing information and by advising on informatics' contributions to health and wellbeing. The Academy should achieve this by elaborating recommendations, distributing best evidence, reporting on important international developments, suggesting research priorities, and other activities.

\section{$\mathrm{V}_{3}$ :The Academy should stimulate progress in informatics research, education, and practice}

Advice can only be valuable if based on solid facts and evidence. To support the advisory role mentioned in $\mathrm{V}_{2}$, the Academy must advance research in the field. This could be achieved by Academy members, e.g. working through committees of the Academy, and producing evidence on certain relevant informatics topic and presenting or publishing their work products. Progress might also be achieved through Academy awards to outstanding informatics research or education or practice with global impact.

\section{$\mathrm{V}_{4}$ : Academy members should share and exchange knowledge}

Academy members should share and exchange their knowledge on important developments in informatics. This should be achieved through both physical and virtual meetings. Topics for discussion should be of international relevance and originality with the potential to have an impact on the visions $\mathrm{V}_{1}$ to $\mathrm{V}_{3}$.

\section{$\mathrm{V}_{5}$ : The Academy's structure and orga- nization should follow the tradition of scientific societies}

The Academy should be organized as a scholarly society, similar to other academies of sciences. This includes the right of co-option allowing nomination and election of its members, based on an extremely careful selection process. This process should be based on the eligibility criteria mentioned in [10] and should consider a scholar's accomplishment, recognition, and global engagement ${ }^{3}$. As an international academy, the Academy should continue to consider regional balance. The number of members younger than a certain age should be limited to a fixed number.

\section{$\mathrm{V}_{6}$ : Academy membership is one of the high-} est honors in informatics internationally

The Academy serves as the international honor society in informatics. As mentioned in [2] "Academy membership will be one of the highest honors in the international field of biomedical and health informatics." A careful selection process and strict eligibility criteria, mentioned in $\mathrm{V}_{5}$, will be an important prerequisite for achieving this. Academy members will be guided by the principle to "practice successful, tolerant, and peaceful collabo-

Let me quote the respective email section of [10]:

„Addendum
Eligibility and Criteria for Election to
Membership in the International Academy
of Health Sciences Informatics (IAHSI)

Membership in the International Academy is intended to be honorific, prestigious, and indicative of substantial achievements, generally with international impact, in the area of biomedical and health informatics. Accordingly, the nomination or election of a candidate for membership should not be taken likely.

To be eligible for election, a nominee should meet the following criteria:

- Accomplishment: The candidate should generally have a high level of training and experience, recognized research achievement and contribution, educational impact, and/or other significant leadership in biomedical and health informatics over a minimum of ten years, and often for much longer.

- Recognition: In those countries or regions where this is possible, it is pertinent if the candidate is an elected member of an academy of sciences or a similar organization.

- Global Engagement: The candidate should be engaged internationally. International involvement can be demonstrated through international activities, in particular in research, publication, education, and/or through international leadership roles in IMIA or in one of the regional international medical informatics organizations of IMIA." 
ration across and beyond our nations and cultures" (see also [6], IMIA statutes, §2.1). Honoring outstanding persons is an important but not the most important activity of the Academy. As in other scholarly societies, receiving the honor of being IAHSI member will hopefully be combined with strong motivations to support and, if possible, actively participate in the activities mentioned before.

\section{$\mathrm{V}_{7}$ : The Academy should meet where IMIA meets}

The Academy has been established under the roof of IMIA with strong links to IMIA and its member societies. The Academy's physical meetings should take place at IMIA meetings, in particular at MedInfo congresses, and at events and places where the annual IMIA General Assembly gathers. Locations and events with IMIA Board meetings may also be considered. Meeting jointly with IMIA serves to achieve two purposes: to remain internationally balanced and to foster the Academy's close relationship to IMIA.

\section{$\mathrm{V}_{8}$ : The Academy's structure and organi- zation should be lean and unbiased}

The Academy's structure and organization should be lean. Closely cooperating with IMIA in this matter will be helpful. As customary for scientific societies, the Academy should be organized in an unbiased fashion without undue influence from any outside sources. Discussions on finances, on statutes, and on other organizational matters (including an appropriate web presence) are of course necessary. They should, however, by no means, become the major activities of this scholarly society. The objectives mentioned before should have priority. Priorities should be ranked as these visions have been ranked, with $\mathrm{V}_{1}$ as highest priority, followed by $\mathrm{V}_{2}$, etc.

\section{Remarks}

It is my hope that presenting these visions will stimulate a fruitful discussion on the Academy's role and development. These visions certainly are subjective. They are intended to stimulate discussions beginning in 2018 at the first Academy meeting. The

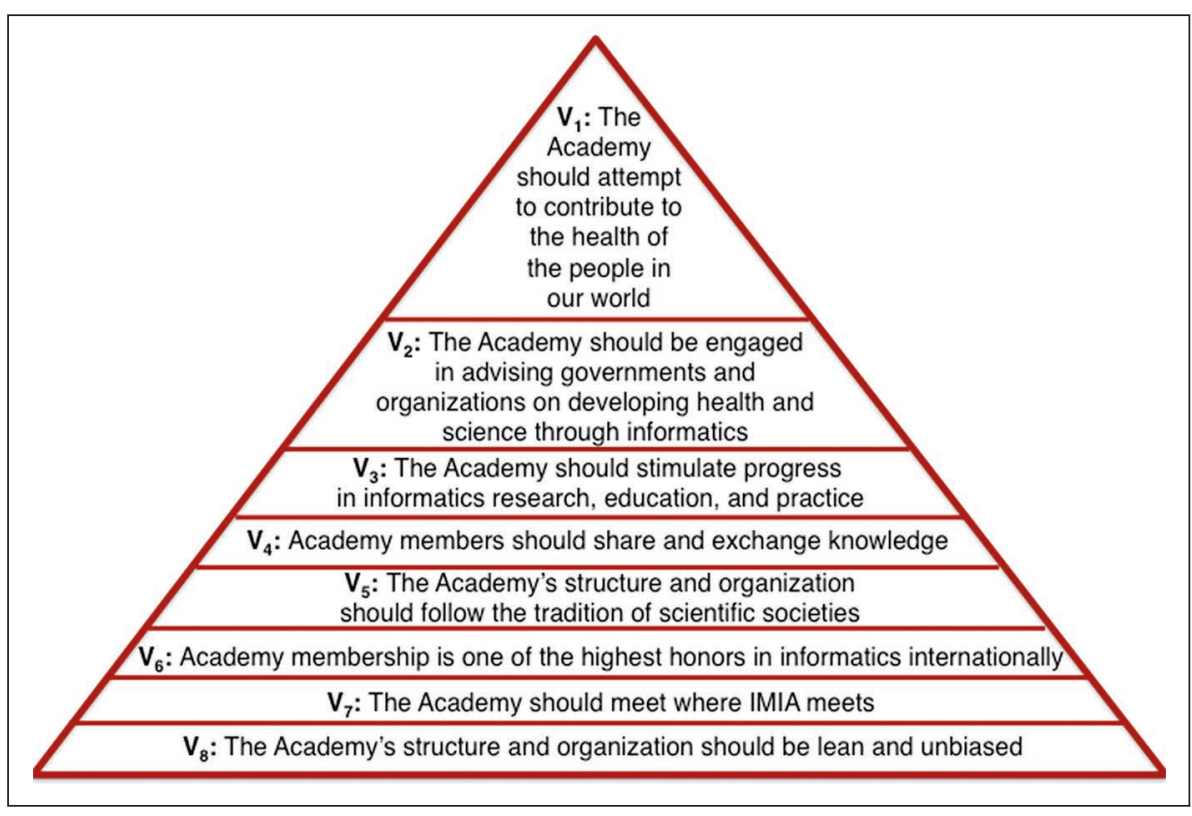

Fig.1 Pyramid of Visions for IAHSI, the International Academy of Health Sciences Informatics, ordered by priority.

Academy is timely, necessary, and of importance. Finding the right path and setting the right priorities through the members of the Academy's inaugural class is crucial for a good and sustainable future.

Figure 1 intents to visualize the visions and their priorities.

\section{Acknowledgements}

My cordial thanks go to Christoph U. Lehmann and Brigitte Séroussi. They kindly edited earlier versions of this manuscript.

\section{References}

1. International Medical Informatics Association establishes the International Academy of Health Sciences Informatics. IMIA announcement on June 6, 2017. http://imia-medinfo.org/wp/internationalmedical-informatics-association-establishesinternational-academy-health-informationsciences-2/. Last access: October 13, 2017.

2. Lehmann CU, Park HA, Shortliffe EH, Degoulet P. The International Academy of Health Sciences Informatics: An Academy of Excellence. Yearb Med Inform 2017;12:7-8.

3. [Braunschweig Scientific Society, BWG] (Braunschweigische Wissenschaftliche Gesellschaft, BWG. Web pages in German). http://bwg-nds.de. Last access: October 13, 2017.

4. Weßelhöft D, Matuschek O. [70 Years Braunschweig Scientific Society. 1943-2013.] (70
Jahre Braunschweigische Wissenschaftliche Gesellschaft. 1943-2013. In German). Braunschweig: BWG; 2013.

5. World Health Organization. eHealth Technical Advisory Group. http://www.who.int/ehealth/tag/ en/. Last access: October 13, 2017.

6. International Medical Informatics Association. http://imia-medinfo.org/wp/. Last access: October 13, 2017.

7. American College of Medical Informatics. https:// www.amia.org/programs/acmi-fellowship. Last access: October 13, 2017.

8. Haux R. Email to Lincoln Assis Moura, Hyeoun-Ae Park, Antoine Geissbuhler, Alexa McCray, and Peter Murray „on establishing an international academy of medical informatics“ from January 10, 2014.

9. Haux R. On determining factors for good research in biomedical and health informatics. Some lessons learned. Yearb Med Inform 2014;9:255-64.

10. Shortliffe T, Degoulet P. Email „to all Nominators of Founding Members of the International Academy of Health Sciences Informatics (IAHSI)" from June 13, 2016.

Correspondence to:

Prof. Dr. Reinhold Haux

Peter L. Reichertz Institute for Medical Informatics

University of Braunschweig - Institute of Technology and

Hannover Medical School

Muehlenpfordtstr. 23

D-38106 Braunschweig

Germany

Tel: +49(0)531 3919500

Fax: +49(0)5313919502

E-mail: Reinhold.Haux@plri.de

www.pli.de 